\title{
Spontaneous ventral spinal epidural hematoma in a child: A case report and review of literature
}

\author{
Shailendra Ratre, Yadram Yadav, Sushma Choudhary ${ }^{1}$, Vijay Parihar \\ Departments of Neurosurgery and ${ }^{1}$ Medicine, Netaji Subhash Chandra Bose Medical College, Jabalpur, Madhya Pradesh, India
}

\section{ABSTRACT}

Spontaneous spinal epidural hematoma is very uncommon cause of spinal cord compression. It is extremely rare in children and is mostly located in dorsal epidural space. Ventral spontaneous spinal epidural hematoma (SSEH) is even rarer, with only four previous reports in childrens. We are reporting fifth such case in a 14 year old male child. He presented with history of sudden onset weakness and sensory loss in both lower limbs with bladder bowel involvment since 15 days. There was no history of trauma or bleeding diasthesis. On clinical examination he had spastic paraplegia. Magnetic resonance imaging (MRI) of dorsal spine was suggestive of ventral spinal epidural hematoma extending from first to sixth dorsal vertebrae. Laminectomy of fourth and fifth dorsal vertebrae and complete evacuation of hematoma was done on the same day of admission. Postoperatively the neurological status was same.

Key words: Coagulopathies, epidural hematoma, spinal hematoma, spontaneous spinal hematoma

\section{Introduction}

Spontaneous spinal epidural hematoma (SSEH) is rare in children. It is usually confined to the dorsal epidural space. Ventral SSEH is rarer, with only four cases reported until date. ${ }^{[1-3]}$ Etiological factors for spinal epidural hematoma are tumors, anticoagulant therapy, coagulopathy, hypertension, arteriovenous malformations, and trauma. Cases without known predisposing factors are known to be spontaneous. Cases with minor trauma are also described as spontaneous. ${ }^{[4,5]}$ Most common presentation is sudden back or neck pain followed by a motor or sensory dysfunction with or without urinary retention. Complete neurological recovery is possible with early diagnosis and urgent surgery while delay in the treatment of this condition causes permanent neurological deficit. We are reporting one such rare case in a child.

\section{Address for correspondence:}

Dr. Shailendra Ratre, Department of Neurosurgery, Netaji Subhash Chandra Bose Medical College, Jabalpur, Madhya Pradesh, India. E-mail: drsratre@gmail.com

\begin{tabular}{|l|l|}
\hline \multicolumn{2}{|c|}{ Access this article online } \\
\hline Quick Response Code: & Website: \\
\hline & www.ruralneuropractice.com \\
\hline & \\
\hline & \\
\hline
\end{tabular}

\section{Case Report}

A previously healthy 14 -year-old boy was admitted with a 15-day history of back pain, urinary retention, and weakness of both lower limbs. The patient noted a rapid increase of his symptoms after 2 days with complete loss of power and sensation in lower limbs. The patient was admitted in some local hospital and came to us after 2 weeks of onset of symptoms. There was no history of spinal trauma, systemic disease, anticoagulant usage, or coagulopathy. Neurological examination revealed bilateral sensory disturbance of all modalities below the level of fourth dorsal vertebrae level and spastic paraplegia. Routine investigations and coagulation profile were normal. T1- and T2-weighted magnetic resonance (MR) images revealed a mass lesion suggesting an epidural hematoma, extending from dorsal vertebrae D1 to dorsal vertebrae D6, localized in the ventral spinal epidural space. There were no signs suggestive of vascular malformations [Figure 1]. The patient was operated on soon after admission. Fourth and fifth

This is an open access article distributed under the terms of the Creative Commons Attribution-NonCommercial-ShareAlike 3.0 License, which allows others to remix, tweak, and build upon the work non-commercially, as long as the author is credited and the new creations are licensed under the identical terms.

For reprints contact: reprints@medknow.com

How to cite this article: Ratre S, Yadav Y, Choudhary S, Parihar V. Spontaneous ventral spinal epidural hematoma in a child: A case report and review of literature. J Neurosci Rural Pract 2016;7:297-9. 


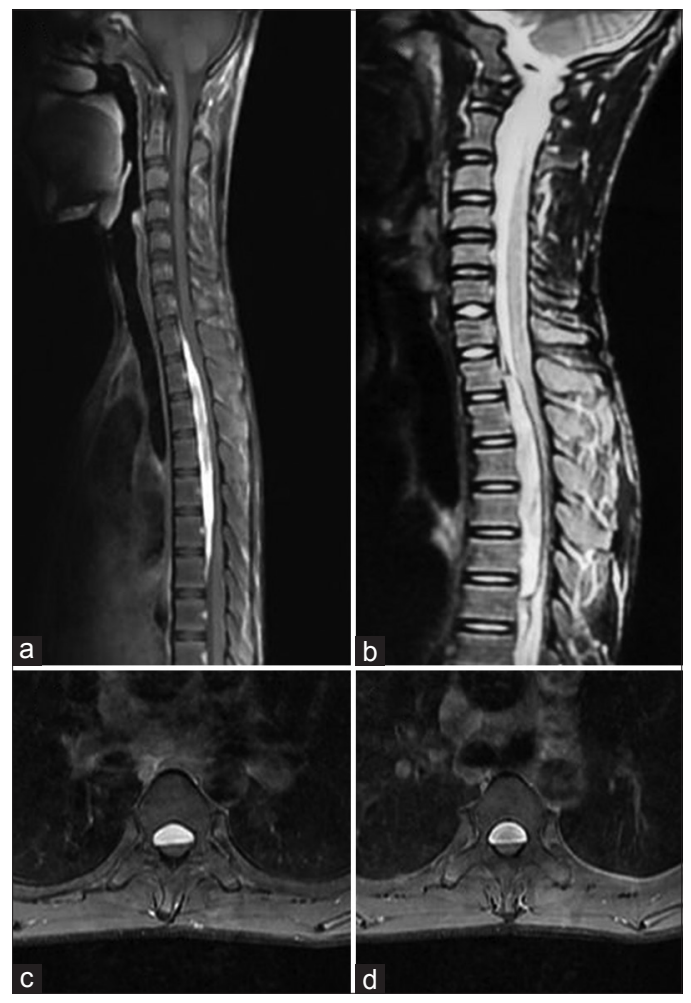

Figure 1: (a) T1-weighted magnetic resonance imaging dorsal spine sagittal cuts, (b) T2-weighted sagittal cuts, (c and d) T2-weighted axial cuts showing a ventral spinal epidural hematoma extending from D1 to D6 vertebra and displacing and compressing the cord posteriorly

dorsal laminectomy with left partial facetectomy was performed, and an epidural clot was totally removed using microneurosurgical technique. During surgery, no vascular abnormality was observed, but no dural pulsation was evident at the end of the procedure. No motor and sensory improvement was achieved postoperatively. An MR sean of the spine was performed 10 days after the operation which showed complete removal of hematoma [Figure 2]. The patient was discharged with the same neurological deficit at the $10^{\text {th }}$ postoperative day.

\section{Discussion}

SSEH is an idiopathic accumulation of blood in the vertebral epidural space. Spinal epidural hematomas are extremely rare in children. The annual incidence of SSEH is almost $0.1 / 100,000$ patients in the general population. This is while this incidence is significantly lower in the pediatric population. ${ }^{[6]}$ It is usually confined to the dorsal epidural space. Ventral SSEH, as our case, is even rarer with only four previous cases reported in the literature. ${ }^{[1-3]}$

Cervicothoracic region is the most common location in children. ${ }^{[2]}$ The most common clinical presentation is

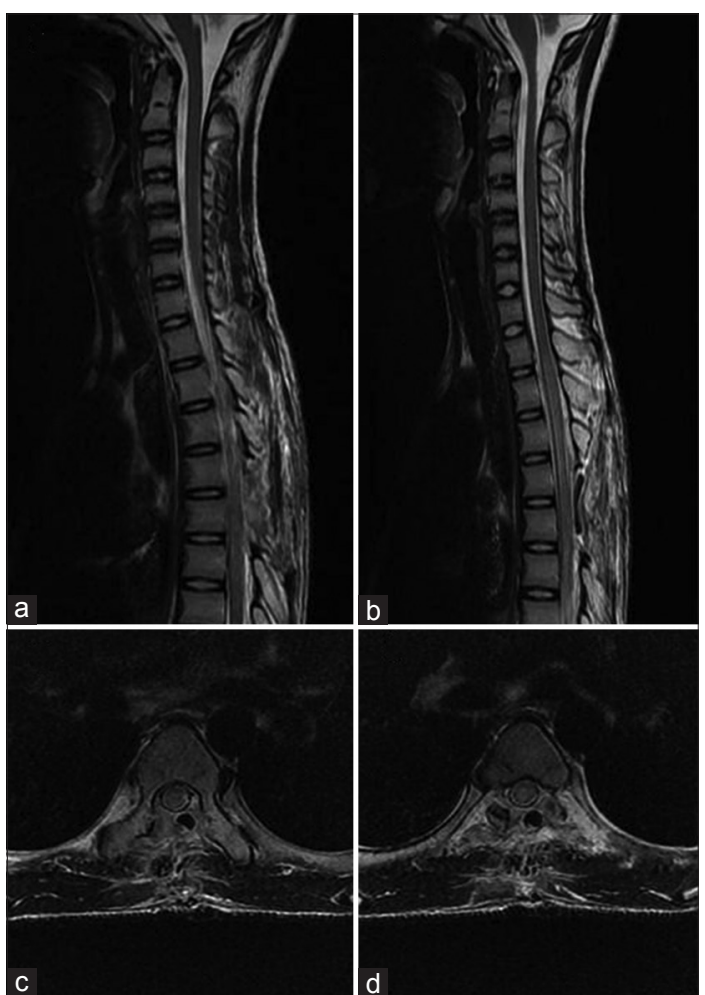

Figure 2: $(a$ and b) T2-weighted postoperative magnetic resonance imaging dorsal spine sagittal cuts, (c and d) T2-weighted axial cuts showing laminectomy defect with complete evacuation of ventral epidural hematoma

sudden back or neck pain followed by motor and sensory dysfunction with or without urinary retention. Signs of progressive spinal cord compression usually occur in hours. The neurologic deficits are dependent to the localization of hematoma, Horner or Brown-Sequard syndromes may be noted. The progression of the symptomatology and clinical signs is usually very rapid, as in our case, although slower progression over a few days has also been reported..$^{[7]}$

Most common causes of spinal epidural hematoma are the use of anticoagulants, ${ }^{[8]}$ coagulopathies (hemophilia ${ }^{[9]}$ and leukemia), and procedures such as a spinal tap or epidural anesthesia. ${ }^{[10]}$ Trauma is rare in children with few cases of it being described. ${ }^{[11]}$ Cases without known predisposing factors are known to be spontaneous. Cases with minor trauma are also described as spontaneous. ${ }^{[4,5]}$

Most authors have contended that SSEH arises from epidural venous plexus in the spinal epidural space. Because of fluctuations in intrathoracic and intra-abdominal pressures after exercise or other maneuvers, reversal of blood flow may induce rupture of a delicate vein in the valveless epidural plexus. Other researchers have proposed the spinal epidural arteries as a source of hemorrhage. ${ }^{[2,12]}$ 
Previously myelography and computerized tomography (CT) were the diagnostic methods for SSEH. Myelography demonstrates classical extradural block image. CT findings are similar to intracranial epidural hematoma showing hyperdense lenticular collection. ${ }^{[13]}$ MR imaging is the best examination for diagnosis and follow-up. ${ }^{[14,15]}$ Sagittal sections disclose a mass located in posterior epidural space. It is clearly outlined with tapering superior and inferior margins. The dura mater is visualized as curvilinear low signal, separating the hematoma from the cord. The hematoma is isointense or slightly hyperintense on T1-weighted images and heterogeneous on T2-weighted images within $24 \mathrm{~h}$ of onset. Later, hematoma gives a high signal on both T1- and T2-weighted sequences. In the absence of any signs suggestive of vascular malformation on MR imaging, preoperative angiography is not essential and need not delay the surgical procedure, because the timing of the surgery, together with the preoperative clinical state, determines the quality of the clinical result. ${ }^{[16]}$

Urgent surgical decompression and evacuation of the epidural hematoma are the treatment of choice. Posteriorly placed hematoma can be easily removed by doing laminectomy but anteriorly placed hematoma needs good exposure and microneurosurgical techniques to prevent retraction injury to the cord. Partial facetectomy can be done in dorsal spine to enhance exposure, and lateral corridor can be used to prevent thecal sac retraction. Complete and partial neurological recovery has been described in approximately $50 \%$ and $44 \%$ of the patients, respectively. ${ }^{[17]}$ Recovery was significantly better when decompression was performed within $<36 \mathrm{~h}$ of the onset of the neurological deficit. There appear to be no factors which promote conservative treatment in SSEH. In the majority of cases with SSEH, the mainstay of treatment will remain surgical decompression of the neural structures and removal of the hematoma. The decision for conservative treatment has to be based on the severity of the neurological deficit and on the clinical course. ${ }^{[18]}$

\section{Conclusion}

SSEH is extremely rare in children. It is a surgical emergency. Prognosis of the patient with SSEH depends on the severity of the neurologic deficit on admission and interval from onset of initial symptom to surgery. Early diagnosis and prompt surgery are crucial to achieve the best neurological outcome and delay in the diagnosis and treatment may cause permanent neurologic deficit.

\section{Financial support and sponsorship \\ Nil.}

\section{Conflicts of interest}

There are no conflicts of interest.

\section{References}

1. Phillips TW, Kling TF Jr., McGillicuddy JE. Spontaneous ventral spinal epidural hematoma with anterior cord syndrome: Report of a case. Neurosurgery 1981;9:440-3.

2. Patel H, Boaz JC, Phillips JP, Garg BP. Spontaneous spinal epidural hematoma in children. Pediatr Neurol 1998;19:302-7.

3. Abbas A, Afzal K, Mujeeb AA, Shahab T, Khalid M. Spontaneous ventral spinal epidural hematoma in an infant: An unusual presentation. Iran J Child Neurol 2013;7:47-50.

4. Patel H, Garg BP. Increasing irritability with sudden onset of flaccid weakness. Semin Pediatr Neurol 1996;3:192-7.

5. Tewari MK, Tripathi LN, Mathuriya SN, Khandelwal N, Kak VK. Spontaneous spinal extradural hematoma in children. Report of three cases and a review of the literature. Childs Nerv Syst 1992;8:53-5.

6. Aminoff MJ. Vascular disorders of the spinal cord. In: Davidoff RA, editor. Handbook of the Spinal Cord. Infections and Cancer. Vol. 5. New York: Marcel Dekker; 1986. p. 271-3.

7. Nagel MA, Taff IP, Cantos EL, Patel MP, Maytal J, Berman D. Spontaneous spinal epidural hematoma in a 7-year-old girl. Diagnostic value of magnetic resonance imaging. Clin Neurol Neurosurg 1989;91:157-60.

8. Penar PL, Fischer DK, Goodrich I, Bloomgarden GM, Robinson F. Spontaneous spinal epidural hematoma. Int Surg 1987;72:218-21.

9. Noth I, Hutter JJ, Meltzer PS, Damiano ML, Carter LP. Spinal epidural hematoma in a hemophilic infant. Am J Pediatr Hematol Oncol 1993;15:131-4.

10. Metzger G, Singbartl G. Spinal epidural hematoma following epidural anesthesia versus spontaneous spinal subdural hematoma. Two case reports. Acta Anaesthesiol Scand 1991;35:105-7.

11. Alva NS. Traumatic spinal epidural hematoma of a 10-month-old male: A clinical note. Pediatr Neurol 2000;23:88-9.

12. Park J, Lee JB, Park JY, Lim DJ, Kim SD, Chung YK. Spinal cord infarction after decompressive laminectomy for spontaneous spinal epidural hematoma - Case report. Neurol Med Chir (Tokyo) 2007;47:325-7.

13. Urculo Bareño E, Arrazola Schlamich M. Spontaneous cervical epidural hematoma. Apropos of a case. Neurochirurgie 1987;33:66-70.

14. Boukobza M, Guichard JP, Boissonet M, George B, Reizine D, Gelbert F, et al. Spinal epidural haematoma: Report of 11 cases and review of the literature. Neuroradiology 1994;36:456-9.

15. Caldarelli M, Di Rocco C, La Marca F. Spontaneous spinal epidural hematoma in toddlers: Description of two cases and review of the literature. Surg Neurol 1994;41:325-9.

16. Lonjon MM, Paquis P, Chanalet S, Grellier P. Nontraumatic spinal epidural hematoma: Report of four cases and review of the literature. Neurosurgery 1997;41:483-6.

17. Pecha MD, Able AC, Barber DB, Willingham AC. Outcome after spontaneous spinal epidural hematoma in children: Case report and review of the literature. Arch Phys Med Rehabil 1998;79:460-3.

18. Groen RJ. Non-operative treatment of spontaneous spinal epidural hematomas: A review of the literature and a comparison with operative cases. Acta Neurochir (Wien) 2004;146:103-10. 